Original Research Paper

\title{
Direct Geometry and Cinematic to the MP-3R Systems
}

\author{
${ }^{1}$ Relly Victoria Petrescu, ${ }^{2}$ Raffaella Aversa, ${ }^{3}$ Bilal Akash, ${ }^{2}$ Antonio Apicella and \\ ${ }^{1}$ Florian Ion Tiberiu Petrescu \\ ${ }^{I}$ ARoTMM-IFToMM, Bucharest Polytechnic University, Bucharest, (CE), Romania \\ ${ }^{2}$ Advanced Material Lab, Department of Architecture and Industrial Design, \\ Second University of Naples, 81031 Aversa (CE), Italy \\ ${ }^{3}$ Dean of School of Graduate Studies and Research, American University of Ras Al Khaimah, UAE
}

Corresponding Author:

Florian Ion Tiberiu Petrescu ARoTMM-IFToMM, Bucharest

Polytechnic University,

Bucharest, (CE), Romania

E-mail: scipub02@gmail.com

\begin{abstract}
Mechatronic robotic systems are today widely used worldwide to ease human work, but especially where work is dangerous, in toxic, radioactive, chemical, explosive atmospheres, without air such as underwater or in the cosmos, or in places hard to reach the man. Robots can take the tedious repetitive work under any circumstances and they can perform a difficult operation for a long time, with no meal or rest breaks. They say the robots have stolen people's jobs. False! Robots have taken from man only those difficult jobs that baptized man and destroyed him. Robots have been created just as a prolongation of man as his real support in the faster, constantly accomplishing of difficult, repetitive, physically and mentally tired work and operations. Robots have emerged many years ago as a requirement of the automotive industry and especially that of road vehicles, especially automobiles. Meanwhile, they have diversified and branched a great deal in almost all industrial spheres. But the most important future of robots must be completely different. They have to help us conquer the cosmic space. The robot must become an extension of man in his divine mission of constructor and conqueror of the universe. Of all the types of industrial robots you use, the most common are the anthropomorphic serial robots, which is why we want to start studying and presenting the robots, with that generally common in robots, anthropomorphic serial systems. The kinematics of serial manipulators and robots will be exemplified for the $3 \mathrm{R}$ cinematic model to a medium difficulty system, ideal for understanding the actual phenomenon, but also for explaining the basic knowledge needed for calculating calculations and simpler or more complex systems. The fixed coordinate system was denoted by $x_{0} O_{0} y_{0} z_{0}$. The mobile systems (rigid) of the three mobile elements $(1,2,3)$ have indices 1,2 and 3 . Their orientation was conveniently chosen but other orientations could be chosen. Known kinematic parameters in the direct kinematics are the absolute rotation angles of the three moving elements: $\varphi_{10}, \varphi_{20}, \varphi_{30}$, angles related to the rotation of the three actuators (electric motors) mounted in the kinematic rotation couplers. The output parameters are the three absolute coordinates $x_{M}, y_{M}, z_{M}$ of point $\mathrm{M}$, ie the kinematic parameters (coordinates) of the end-effector (the actuator element (the final), which can be a grasping hand, a solder tip, painted, cut, etc ...).
\end{abstract}

Keywords: Cinematic of the MP-3R Systems, Geometry, Kinematic Parameters

work is dangerous, in toxic, radioactive, chemical, explosive atmospheres, without air such as underwater or in the cosmos, or in places hard to reach the man.

\section{Introduction}

Mechatronic robotic systems are today widely used worldwide to ease human work, but especially where 
Robots can take the tedious repetitive work under any circumstances and they can perform a difficult operation for a long time, with no meal or rest breaks. They say the robots have stolen people's jobs. False! Robots have taken from man only those difficult jobs that baptized man and destroyed him. Robots have been created just as a prolongation of man as his real support in the faster, constantly accomplishing of difficult, repetitive, physically and mentally tired work and operations. Robots have emerged many years ago as a requirement of the automotive industry and especially that of road vehicles, especially automobiles. Meanwhile, they have diversified and branched a great deal in almost all industrial spheres. But the most important future of robots must be completely different. They have to help us conquer the cosmic space. The robot must become an extension of man in his divine mission of constructor and conqueror of the universe. Of all the types of industrial robots you use, the most common are the anthropomorphic serial robots, which is why we want to start studying and presenting the robots, with that generally common in robots, anthropomorphic serial systems (Antonescu and Petrescu, 1985; 1989; Antonescu et al., 1985a-b, 1986; 1987; 1988; 1994; 1997; 2000a-b, 2001; Aversa et al., 2017a-e, 2016a-o; Berto et al., 2016a-d; Cao et al., 2013; Dong et al., 2013; Comanescu, 2010; Franklin, 1930; He et al., 2013; Lee, 2013; Lin et al., 2013; Liu et al., 2013; Mirsayar et al., 2017; Padula and Perdereau, 2013; Perumaal and Jawahar, 2013; Petrescu, 2011; 2015a-b; Petrescu and Petrescu, 1995a-b; 1997a-c; 2000a-b; 2002ab; 2003; 2005a-e; 2011; 2012a-b; 2013a-b; 2016a-c; Petrescu et al., 2009; 2016; 2017a-l).

\section{Materials and Methods}

The kinematics of serial manipulators and robots will be exemplified for the $3 \mathrm{R}$ cinematic model (Figure 1), a medium difficulty system, ideal for understanding the actual phenomenon, but also for explaining the basic knowledge needed for calculating calculations and simpler or more complex systems.

The fixed coordinate system was denoted by $x_{0} O_{0} y_{0} z_{0}$. The mobile systems (rigid) of the three mobile elements $(1,2,3)$ have indices 1,2 and 3 . Their orientation was conveniently chosen but other orientations could be chosen. Known kinematic parameters in the direct kinematics are the absolute rotation angles of the three moving elements: $\varphi_{10}, \varphi_{20}, \varphi_{30}$, angles related to the rotation of the three actuators (electric motors) mounted in the kinematic rotation couplers. The output parameters are the three absolute coordinates $x_{M}, y_{M}, z_{M}$ of point $\mathrm{M}$, i.e., the kinematic parameters (coordinates) of the end-effector (the actuator element (the final), which can be a grasping hand, a solder tip, painted, cut, etc ...).

To begin with, write the vector matrix $\left(A_{01}\right)$ to change the coordinates of the origin of the coordinate system by translating from $O_{0}$ to $O_{1}$, the axes remain parallel to themselves at all times (1):

$A_{01}=\left[\begin{array}{l}0 \\ 0 \\ a_{1}\end{array}\right]$

Next, write the $T_{01}$ rotation matrix of the system $x_{1} O_{1} y_{1} z_{1}$ to the system $x_{0} O_{0} y_{0} z_{0}$, (this is a square matrix $3 \times 3),(2)$ :

$T_{01}\left[\begin{array}{ccc}\alpha_{x} & \beta_{x} & \gamma_{x} \\ \alpha_{y} & \beta_{y} & \gamma_{y} \\ \alpha_{z} & \beta_{z} & \gamma_{z}\end{array}\right]=\left[\begin{array}{ccc}\cos \phi_{10} & -\sin \phi_{10} & 0 \\ \sin \phi_{10} & \cos \phi_{10} & 0 \\ 0 & 0 & 1\end{array}\right]$

On the first column (belonging to the coordinates of $\left.O_{1} x_{1}\right)$ the coordinates of the $O_{1} x_{1}$ unit vector the axes of the old system $x_{0} O_{0} y_{0} z_{0}$ are passed; it is practically the projections of the $O_{1} x_{1}$ unit vector on the axes of the old $x_{0} O_{0} y_{0} z_{0}$ coordinate system translated into $O_{1}$ (but not rotated, thus only the actual rotation without translation) occurs (3):

$\left[\begin{array}{l}\alpha_{x} \\ \alpha_{y} \\ \alpha_{z}\end{array}\right]$

On the second column of the $T_{01}$ matrix, the coordinates of the $O_{1} y_{1}$ axis unit vector the axes of the old $x_{0} O_{0} y_{0} z_{0}$ system are translated into $O_{1}$ without rotation (basically the coordinates of this unit vector the old translational but non-rotating reference axes), (4):

$\left[\begin{array}{l}\beta_{x} \\ \beta_{y} \\ \beta_{z}\end{array}\right]$

On the third column of the $T_{01}$ matrix, the coordinates of the $O_{1} z_{1}$ axis unit vector the axes of the old system $x_{0} O_{0} y_{0} z_{0}$ are translated into $O_{1}$ without rotation (basically the coordinates of this unit vector the old referenced but non-routed reference axes), (5):

$\left[\begin{array}{l}\gamma_{x} \\ \gamma_{y} \\ \gamma_{z}\end{array}\right]$

In the chosen case, the unit vector of $O_{1} x_{1}$ (the unit vector always has module (1) has the following coordinates compared to the old axle system $x_{0} O_{0} y_{0} z_{0}$ translated into $O_{1}$ without rotation (6): 


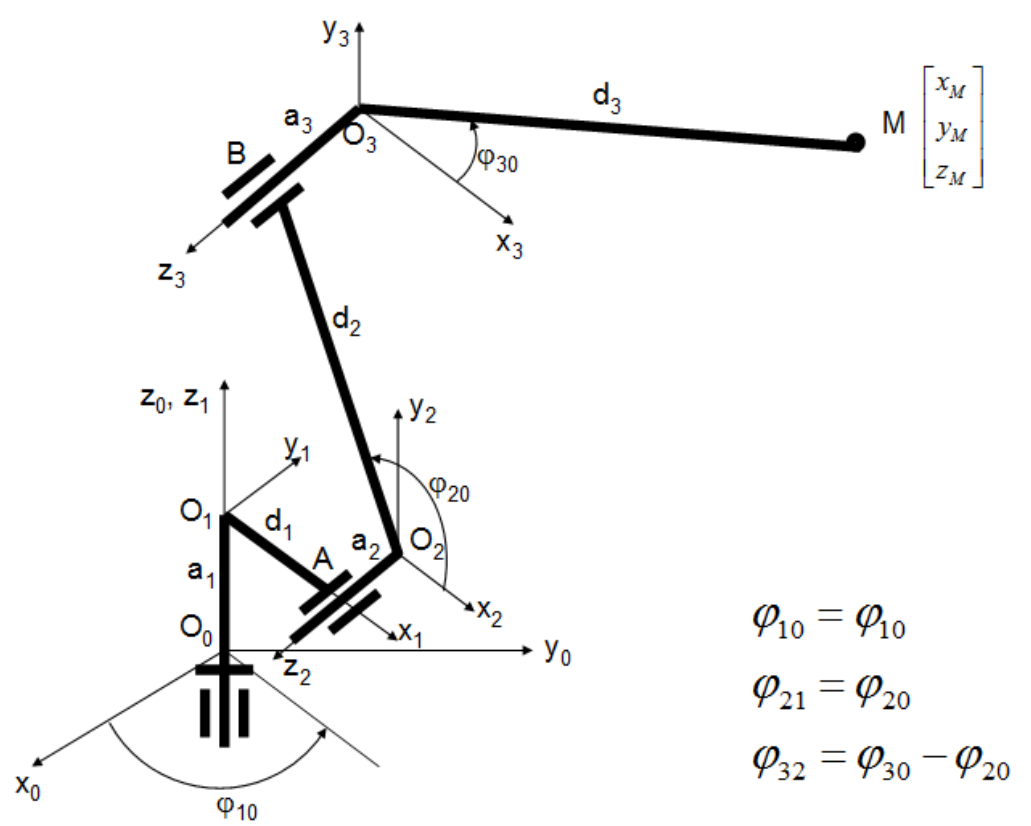

Fig. 1: The geometry and cinematic of a MP-3R

$\left[\begin{array}{l}\alpha_{x}=1 \cdot \cos \phi_{10}=\cos \phi_{10} \\ \alpha_{y}=1 \cdot \sin \phi_{10}=\sin \phi_{10} \\ \alpha_{z}=1 \cdot \cos 90^{\circ}=1 \cdot 0=0\end{array}\right]$

$O_{1} y_{1}$ 's unit vector has the following coordinates in relation to the old $x_{0} O_{0} y_{0} z_{0}$ axis system (7):

$\left[\begin{array}{l}\beta_{x}=-1 \cdot \sin \phi_{10}=-\sin \phi_{10} \\ \beta_{y}=1 \cdot \cos \phi_{10}=\cos \phi_{10} \\ \beta_{z}=1 \cdot \cos 90^{\circ}=1 \cdot 0=0\end{array}\right]$

$O_{1} z_{1}$ 's unit vector has the following coordinates in relation to the old $x_{0} O_{0} y_{0} z_{0}$ axis system translated into $O_{1}$ without rotation $(8)$ :

$\left[\begin{array}{l}\gamma_{x}=1 \cdot \cos 90^{\circ}=1 \cdot 0=0 \\ \gamma_{y}=1 \cdot \cos 90^{\circ}=1 \cdot 0=0 \\ \gamma_{z}=1 \cdot \cos 0^{\circ}=1 \cdot 1=1\end{array}\right]$

See matrix $T_{01}$ obtained (relationship 2).

The transition from the $x_{1} O_{1} y_{1} z_{1}$ system to the $x_{2} \mathrm{O}_{2} y_{2} z_{2}$ coordinate system is done in two distinct stages. The first is a translation of the whole system such that (the axes being parallel to themselves) central $O_{1}$ to move to $\mathrm{O}_{2}$; then the second stage takes place in which there is a rotation of the system rotating axes and the center $O$ remains permanently fixed. The system translation from 1 to 2 is marked by the column vector type $A_{12}(9)$ :
$A_{12}=\left[\begin{array}{l}d_{1} \\ a_{2} \\ 0\end{array}\right]$

On the old $O_{1} x_{1}$ axis, $O_{2}$ was translated with $d_{1}, O_{1} y_{1}$, $\mathrm{O}_{2}$ was translated with $a_{2}$ and $O_{2} z_{1}$ was not translated.

$\mathrm{O}_{2} x_{2}$ 's unit vector, the $x_{1} O_{1} y_{1} z_{1}$ system (translated, but not rotated) coordinates (10):

$\alpha_{x}=1 ; \quad \alpha_{y}=0 ; \quad \alpha_{z}=0$

$\mathrm{O}_{2} \mathrm{y}_{2}$ 's unit vector has in relation to the $x_{1} O_{1} y_{1} z_{1}$ system translated into $\mathrm{O}_{2}$ (not rotated) the coordinates (11):

$\beta_{x}=0 ; \beta_{y}=0 ; \beta_{z}=1$

Because now $O_{2} y_{2}$, was taken the new $O_{1} z_{1}$ axis:

The $O_{2} z_{2}$ unit vector has, in relation to the $x_{1} O_{1} y_{1} z_{1}$ system, translated into $\mathrm{O}_{2}$ (not rotated) the coordinates (12):

$\gamma_{x}=0 ; \gamma_{y}=-1 ; \gamma_{z}=0$

Since the $O_{2} z_{2}$ axis took the place of the $O_{1} y_{1}$ axis, it was of the opposite direction.

The square of the transfer (rotation) is written (13):

$T_{12}=\left[\begin{array}{ccc}\alpha_{x} & \beta_{x} & \gamma_{x} \\ \alpha_{y} & \beta_{y} & \gamma_{y} \\ \alpha_{z} & \beta_{z} & \gamma_{z}\end{array}\right]=\left[\begin{array}{ccc}1 & 0 & 0 \\ 0 & 0 & -1 \\ 0 & 1 & 0\end{array}\right]$ 
The transition from the $x_{2} \mathrm{O}_{2} y_{2} z_{2}$ system to the $x_{3} O_{3} y_{3} z_{3}$ coordinate system is also done in two distinct stages, one translation and one rotation.

$\mathrm{O}_{2}$ translates into $\mathrm{O}_{3}$ (the axes are kept parallel to themselves), (14):

$$
A_{23}=\left[\begin{array}{l}
d_{2} \cdot \cos \phi_{20} \\
d_{2} \cdot \sin \phi_{20} \\
-a_{3}
\end{array}\right]
$$

Then $\mathrm{O}_{3}$ stands and the axes rotate. The unit vector of $\mathrm{O} 3 \times 3$ has, in relation to the axes system $x_{2} \mathrm{O}_{2} y_{2} z_{2}$, translated in $O_{3}$ (unrotated) the coordinates $\alpha$ (15):

$\alpha_{x}=1 ; \alpha_{y}=0 ; \alpha_{z}=0$

$\mathrm{O}_{3} y_{3}$ 's unit vector the $x_{2} \mathrm{O}_{2} y_{2} z_{2}$ axis system is translated into $\mathrm{O}_{3}$ (without to be rotated) coordinates $\beta$ (16):

$\beta_{x}=0 ; \beta_{y}=1 ; \beta_{z}=0$

$\mathrm{O}_{3} z_{3}$ 's unit vector the $x_{2} \mathrm{O}_{2} y_{2} z_{2}$ axis system translated into $\mathrm{O}_{3}$ (not rotated) coordinates $\gamma(17)$ :

$\gamma_{x}=0 ; \gamma_{y}=0 ; \gamma_{z}=1$

Practically, the $x_{3} O_{3} y_{3} z_{3}$ did not turn at all at all against the $x_{2} \mathrm{O}_{2} y_{2} z_{2}$ system (from 2 to 3 only a translation took place). The matrix of rotation in this case is the unit matrix (18):

$T_{23}\left[\begin{array}{ccc}\alpha_{x} & \beta_{x} & \gamma_{x} \\ \alpha_{y} & \beta_{y} & \gamma_{y} \\ \alpha_{z} & \beta_{z} & \gamma_{z}\end{array}\right]=\left[\begin{array}{ccc}1 & 0 & 0 \\ 0 & 1 & 0 \\ 0 & 0 & 1\end{array}\right]$

The vector matrix (column) that positions the $M$ point in the $x_{3} O_{3} y_{3} z_{3}$ coordinate system is written (19):

$X_{3 M}=\left[\begin{array}{l}x_{3 M} \\ y_{3 M} \\ z_{3 M}\end{array}\right]=\left[\begin{array}{l}d_{3} \cdot \cos \phi_{30} \\ d_{3} \cdot \sin \phi_{30} \\ 0\end{array}\right]$

The coordinates of the point $M$ in the system (2) $x_{2} \mathrm{O}_{2} y_{2} z_{2}$ (i.e., towards it) are obtained by a matrix transformation of the form (20):

$X_{2 M}=A_{23}+T_{23} \cdot X_{3 M}$

Perform the matrix product first (21):

$$
\begin{aligned}
& T_{23} \cdot X_{3 M}=\left[\begin{array}{lll}
1 & 0 & 0 \\
0 & 1 & 0 \\
0 & 0 & 1
\end{array}\right] \cdot\left[\begin{array}{l}
d_{3} \cdot \cos \phi_{30} \\
d_{3} \cdot \sin \phi_{30} \\
0
\end{array}\right] \\
& =\left[\begin{array}{l}
d_{3} \cdot \cos \phi_{30} \\
d_{3} \cdot \sin \phi_{30} \\
0
\end{array}\right]
\end{aligned}
$$

Calculate then $X_{2 M}(22)$ :

$$
\begin{aligned}
& X_{2 M}=A_{23}+T_{23} \cdot X_{3 M} \\
& =\left[\begin{array}{l}
d_{2} \cdot \cos \phi_{20} \\
d_{2} \cdot \sin \phi_{20} \\
-a_{3}
\end{array}\right]+\left[\begin{array}{l}
d_{3} \cdot \cos \phi_{30} \\
d_{3} \cdot \sin \phi_{30} \\
0
\end{array}\right] \\
& =\left[\begin{array}{l}
d_{2} \cdot \cos \phi_{20}+d_{3} \cdot \cos \phi_{30} \\
d_{2} \cdot \sin \phi_{20}+d_{3} \cdot \sin \phi_{30} \\
-a_{3}
\end{array}\right]
\end{aligned}
$$

The coordinates of the $M$ point in (against) the system (1) $x_{1} O_{1} y_{1} z_{1}$ are obtained as follows (23-25):

$X_{1 M}=A_{12}+T_{12} \cdot X_{2 M}$

$T_{12} \cdot X_{2 M}$

$=\left[\begin{array}{ccc}1 & 0 & 0 \\ 0 & 0 & -1 \\ 0 & 1 & 0\end{array}\right] \cdot\left[\begin{array}{ccc}d_{2} \cdot \cos \phi_{20} & + & d_{3} \cdot \cos \phi_{30} \\ d_{2} \cdot \sin \phi_{20} & + & d_{3} \cdot \sin \phi_{30} \\ & -a_{3} & \end{array}\right]$

$=\left[\begin{array}{lll}d_{2} \cdot \cos \phi_{20} & + & d_{3} \cdot \cos \phi_{30} \\ & a_{3} & \\ d_{2} \cdot \sin \phi_{20} & + & d_{3} \cdot \sin \phi_{30}\end{array}\right]$

$X_{1 M}=A_{12}+T_{12} \cdot X_{2 M}$

$=\left[\begin{array}{l}d_{1} \\ a_{2} \\ 0\end{array}\right]+\left[\begin{array}{l}d_{2} \cdot \cos \phi_{20}+d_{3} \cdot \cos \phi_{30} \\ a_{3} \\ d_{2} \cdot \sin \phi_{20}+d_{3} \cdot \sin \phi_{30}\end{array}\right]$

$=\left[\begin{array}{l}d_{1}+d_{2} \cdot \cos \phi_{20}+d_{3} \cdot \cos \phi_{30} \\ a_{2}+a_{3} \\ d_{2} \cdot \sin \phi_{20}+d_{3} \cdot \sin \phi_{30}\end{array}\right]$

The coordinates of point $M$ in the fixed system $x_{0} O_{0} y_{0} z_{0}$ are written (26-28):

$X_{0 M}=A_{01}+T_{01} \cdot X_{1 M}$

$T_{01} \cdot X_{1 M}=$

$\cdot\left[\begin{array}{ccc}d_{3} \cdot \sin \phi_{30} & \sin \phi_{10} & 0 \\ \sin \phi_{10} & \cos \phi_{10} & 0 \\ 0 & 0 & 1\end{array}\right] \cdot\left[\begin{array}{c}d_{1}+d_{2} \cdot \cos \phi_{20}+d_{3} \cdot \cos \phi_{30} \\ a_{2}+a_{3} \\ d_{2} \cdot \sin \phi_{20}+d_{3} \cdot \sin \phi_{30}\end{array}\right]$

$T_{01} \cdot X_{1 M}=$

$\left[\begin{array}{l}\left(d_{1}+d_{2} \cdot \cos \phi_{20}+d_{3} \cdot \cos \phi_{30}\right) \\ \cdot \cos \phi_{10}-\left(a_{2}+a_{3}\right) \cdot \sin \phi_{10} \\ \left(d_{1}+d_{2} \cdot \cos \phi_{20}+d_{3} \cdot \cos \phi_{30}\right) \\ \cdot \sin \phi_{10}+\left(a_{2}+a_{3}\right) \cdot \cos \phi_{10} \\ d_{2} \cdot \sin \phi_{20}+d_{3} \cdot \sin \phi_{30}\end{array}\right]$ 


$$
\begin{aligned}
& X_{0 M}=A_{01}+T_{01} \cdot X_{1 M} \\
& =\left[\begin{array}{l}
0 \\
0 \\
a_{1}
\end{array}\right]+\left[\begin{array}{l}
\left(d_{1}+d_{2} \cdot \cos \phi_{20}+d_{3} \cdot \cos \phi_{30}\right) \\
\cdot \cos \phi_{10}-\left(a_{2}+a_{3}\right) \cdot \sin \phi_{10} \\
\left(d_{1}+d_{2} \cdot \cos \phi_{20}+d_{3} \cdot \cos \phi_{30}\right) \\
\cdot \sin \phi_{10}+\left(a_{2}+a_{3}\right) \cdot \cos \phi_{10} \\
d_{2} \cdot \sin \phi_{20}+d_{3} \cdot \sin \phi_{30}
\end{array}\right] \\
& =\left[\begin{array}{l}
\left(d_{1}+d_{2} \cdot \cos \phi_{20}+d_{3} \cdot \cos \phi_{30}\right) \\
\cdot \cos \phi_{10}-\left(a_{2}+a_{3}\right) \cdot \sin \phi_{10} \\
\left(d_{1}+d_{2} \cdot \cos \phi_{20}+d_{3} \cdot \cos \phi_{30}\right) \\
\cdot \sin \phi_{10}+\left(a_{2}+a_{3}\right) \cdot \cos \phi_{10} \\
a_{1}+d_{2} \cdot \sin \phi_{20}+d_{3} \cdot \sin \phi_{30}
\end{array}\right]
\end{aligned}
$$

$X_{0 M}$ takes the form of (29):

$$
\begin{aligned}
& X_{0 M}=\left[\begin{array}{l}
x_{M} \\
y_{M} \\
z_{M}
\end{array}\right]= \\
& {\left[\begin{array}{l}
d_{1} \cdot \cos \phi_{10}-a_{2} \cdot \sin \phi_{10}+d_{2} \cdot \cos \phi_{20} \cdot \cos \phi_{10} \\
-a_{3} \cdot \sin \phi_{10}+d_{3} \cdot \cos \phi_{30} \cdot \cos \phi_{10} \\
d_{1} \cdot \sin \phi_{10}+a_{2} \cdot \cos \phi_{10}+d_{2} \cdot \cos \phi_{20} \cdot \sin \phi_{10} \\
+a_{3} \cdot \cos \phi_{10}+d_{3} \cdot \cos \phi_{30} \cdot \sin \phi_{10} \\
a_{1}+d_{2} \cdot \sin \phi_{20}+d_{3} \cdot \sin \phi_{30}
\end{array}\right]}
\end{aligned}
$$

\section{Results}

The same calculations will be further pursued by a direct method, taking into account the matrix calculations (30a):

$$
\begin{aligned}
& X_{0 M}=A_{01}+T_{01} \cdot X_{1 M}=A_{01}+T_{01} \cdot\left(A_{12}+T_{12} \cdot X_{2 M}\right)= \\
& =A_{01}+T_{01} \cdot A_{12}+T_{01} \cdot T_{12} \cdot X_{2 M}= \\
& =A_{01}+T_{01} \cdot A_{12}+T_{01} \cdot T_{12} \cdot\left(A_{23}+T_{23} \cdot X_{3 M}\right)= \\
& =A_{01}+T_{01} \cdot A_{12}+T_{01} \cdot T_{12} \cdot A_{23}+T_{01} \cdot T_{12} \cdot T_{23} \cdot X_{3 M}
\end{aligned}
$$

The relationship is retained $(30 \mathrm{~b})$ :

$$
X_{0 M}=A_{01}+T_{01} \cdot A_{12}+T_{01} \cdot T_{12} \cdot A_{23}+T_{01} \cdot T_{12} \cdot T_{23} \cdot X_{3 M}
$$

Perform matrix products in the expression (30') while remaining in the form of a matrix amount (31-36):

$$
\begin{aligned}
& T_{01} \cdot A_{12}=\left[\begin{array}{ccc}
\cos \phi_{10} & -\sin \phi_{10} & 0 \\
\sin \phi_{10} & \cos \phi_{10} & 0 \\
0 & 0 & 1
\end{array}\right] \cdot\left[\begin{array}{l}
d_{1} \\
a_{2} \\
0
\end{array}\right] \\
& =\left[\begin{array}{l}
d_{1} \cdot \cos \phi_{10}-a_{2} \cdot \sin \phi_{10} \\
d_{1} \cdot \sin \phi_{10}+a_{2} \cdot \cos \phi_{10} \\
0
\end{array}\right]
\end{aligned}
$$

$$
\begin{aligned}
& T_{01} \cdot T_{12}=\left[\begin{array}{ccc}
\cos \phi_{10} & -\sin \phi_{10} & 0 \\
\sin \phi_{10} & \cos \phi_{10} & 0 \\
0 & 0 & 1
\end{array}\right] \cdot\left[\begin{array}{ccc}
1 & 0 & 0 \\
0 & 0 & -1 \\
0 & 1 & 0
\end{array}\right] \\
& =\left[\begin{array}{ccc}
\cos \phi_{10} & 0 & \sin \phi_{10} \\
\sin \phi_{10} & 0 & -\cos \phi_{10} \\
0 & 1 & 0
\end{array}\right]
\end{aligned}
$$

$T_{01} \cdot T_{12} \cdot A_{23}=$

$=\left[\begin{array}{ccc}\cos \phi_{10} & 0 & \sin \phi_{10} \\ \sin \phi_{10} & 0 & -\cos \phi_{10} \\ 0 & 1 & 0\end{array}\right] \cdot\left[\begin{array}{l}d_{2} \cdot \cos \phi_{20} \\ d_{2} \cdot \sin \phi_{20} \\ -a_{3}\end{array}\right]$

$=\left[\begin{array}{l}d_{2} \cdot \cos \phi_{10} \cdot \cos \phi_{20}-a_{3} \cdot \sin \phi_{10} \\ d_{2} \cdot \sin \phi_{10} \cdot \cos \phi_{20}+a_{3} \cdot \cos \phi_{10} \\ d_{2} \cdot \sin \phi_{20}\end{array}\right]$

$T_{01} \cdot T_{12} \cdot T_{23}=$

$=\left[\begin{array}{ccc}\cos \phi_{10} & 0 & \sin \phi_{10} \\ \sin \phi_{10} & 0 & -\cos \phi_{10} \\ 0 & 1 & 0\end{array}\right] \cdot\left[\begin{array}{ccc}1 & 0 & 0 \\ 0 & 1 & 0 \\ 0 & 0 & 1\end{array}\right]$

$=\left[\begin{array}{ccc}\cos \phi_{10} & 0 & \sin \phi_{10} \\ \sin \phi_{10} & 0 & -\cos \phi_{10} \\ 0 & 1 & 0\end{array}\right]$

$T_{01} \cdot T_{12} \cdot T_{23} \cdot X_{3 M}=$

$=\left[\begin{array}{llc}\cos \phi_{10} & 0 & \sin \phi_{10} \\ \sin \phi_{10} & 0 & -\cos \phi_{10} \\ 0 & 1 & 0\end{array}\right] \cdot\left[\begin{array}{l}d_{3} \cdot \cos \phi_{30} \\ d_{3} \cdot \sin \phi_{30} \\ 0\end{array}\right]$

$=\left[\begin{array}{lll}d_{3} \cdot \cos \phi_{10} & \cdot & \cos \phi_{30} \\ d_{3} \cdot \sin \phi_{10} & \cdot & \cos \phi_{30} \\ d_{3} \cdot \sin \phi_{30} & \end{array}\right]$

$X_{0 M}=\left[\begin{array}{l}0 \\ 0 \\ a_{1}\end{array}\right]+\left[\begin{array}{l}d_{1} \cdot \cos \phi_{10}-a_{2} \cdot \sin \phi_{10} \\ d_{1} \cdot \sin \phi_{10}+a_{2} \cdot \cos \phi_{10} \\ 0\end{array}\right]$

$+\left[\begin{array}{l}d_{2} \cdot \cos \phi_{10} \cdot \cos \phi_{20}-a_{3} \cdot \sin \phi_{10} \\ d_{2} \cdot \sin \phi_{10} \cdot \cos \phi_{20}+a_{3} \cdot \cos \phi_{10} \\ d_{2} \cdot \sin \phi_{20}\end{array}\right]+\left[\begin{array}{l}d_{3} \cdot \cos \phi_{10} \cdot \cos \phi_{30} \\ d_{3} \cdot \sin \phi_{10} \cdot \cos \phi_{30} \\ d_{3} \cdot \sin \phi_{30}\end{array}\right]$

$$
=\left[\begin{array}{l}
x_{M} \\
y_{M} \\
z_{M}
\end{array}\right]=\left[\begin{array}{l}
d_{1} \cdot \cos \phi_{10}-a_{2} \cdot \sin \phi_{10}+d_{2} \cdot \cos \phi_{20} \cdot \cos \phi_{10} \\
-a_{3} \cdot \sin \phi_{10}+d_{3} \cdot \cos \phi_{30} \cdot \cos \phi_{10} \\
d_{1} \cdot \sin \phi_{10}+a_{2} \cdot \cos \phi_{10}+d_{2} \cdot \cos \phi_{20} \cdot \sin \phi_{10} \\
+a_{3} \cdot \cos \phi_{10}+d_{3} \cdot \cos \phi_{30} \cdot \sin \phi_{10} \\
a_{1}+d_{2} \cdot \sin \phi_{20}+d_{3} \cdot \sin \phi_{30}
\end{array}\right]
$$

\section{Discussion}

Direct kinematics obtains the Cartesian coordinates $x_{M}, y_{M}, z_{M}$ of the point $M$ (the end effector) according to 
the three independent angular displacements $\varphi_{10}, \varphi_{20}$, $\varphi_{30}$, obtained with actuators (37-38).

$\left\{\begin{array}{l}x_{M}=f_{x}\left(\phi_{10}, \phi_{20}, \phi_{30}\right) \\ y_{M}=f_{y}\left(\phi_{10}, \phi_{20}, \phi_{30}\right) \\ z_{M}=f_{z}\left(\phi_{10}, \phi_{20}, \phi_{30}\right)\end{array}\right.$

$\left\{\begin{array}{l}x_{M}=d_{1} \cdot \cos \phi_{10}-a_{2} \cdot \sin \phi_{10}+d_{2} \cdot \cos \phi_{20} \cdot \cos \phi_{10} \\ -a_{3} \cdot \sin \phi_{10}+d_{3} \cdot \cos \phi_{30} \cdot \cos \phi_{10} \\ y_{M}=d_{1} \cdot \sin \phi_{10}+a_{2} \cdot \cos \phi_{10}+d_{2} \cdot \cos \phi_{20} \cdot \sin \phi_{10} \\ +a_{3} \cdot \cos \phi_{10}+d_{3} \cdot \cos \phi_{30} \cdot \sin \phi_{10} \\ z_{M}=a_{1}+d_{2} \cdot \sin \phi_{20}+d_{3} \cdot \sin \phi_{30}\end{array}\right.$

The calculations are made with absolute angular displacements, but actuator displacements do not all coincide with the independent ones. They are thus determined (39):

$$
\begin{aligned}
& \phi_{10}=\phi_{10} \\
& \phi_{21}=\phi_{20} \\
& \phi_{32}=\phi_{30}-\phi_{20}
\end{aligned}
$$

The first two relative rotations of the actuators coincide with the independent rotation (used in the calculations), but the third relative rotation of the last actuator is obtained as a difference between two absolute rotations.

Speeds and accelerations are obtained by deriving relationships (38) over time.

\section{Conclusion}

The work presents an analytical method for determination of cinematic parameters in a $3 \mathrm{R}$ robotics module.

An exact algebraic, matrix, calculation method is presented.

Direct kinematics obtains the Cartesian coordinates $x_{M}, y_{M}, z_{M}$ of the point $M$ (the end effector) according to the three independent angular displacements $\varphi_{10}, \varphi_{20}$, $\varphi_{30}$, obtained with actuators (37-38).

The calculations are made with absolute angular displacements, but actuator displacements do not all coincide with the independent ones. They are thus determined (39).

\section{Acknowledgement}

This text was acknowledged and appreciated by Dr. Veturia CHIROIU Honorific member of Technical Sciences Academy of Romania (ASTR) PhD supervisor in Mechanical Engineering.

\section{Funding Information}

Research contract: 1-Research contract: Contract number 36-5-4D/1986 from 24IV1985, beneficiary CNST RO (Romanian National Center for Science and Technology) Improving dynamic mechanisms.

2-Contract research integration. 19-91-3 from 29.03.1991; Beneficiary: MIS; TOPIC: Research on designing mechanisms with bars, cams and gears, with application in industrial robots.

3-Contract research. GR 69/10.05.2007: NURC in 2762; theme 8: Dynamic analysis of mechanisms and manipulators with bars and gears.

4-Labor contract, no. 35/22.01.2013, the UPB, "Stand for reading performance parameters of kinematics and dynamic mechanisms, using inductive and incremental encoders, to a Mitsubishi Mechatronic System" "PN-IIIN-CI-2012-1-0389".

All these matters are copyrighted! Copyrights: 394qodGnhhtej, from 17-02-2010 13:42:18; 463-vpstuCGsiy, from 20-03-2010 12:45:30; 631-sqfsgqvutm, from 24-052010 16:15:22; 933-CrDztEfqow, from 07-01-2011 13:37:52.

\section{Author's Contributions}

This section should state the contributions made by each author in the preparation, development and publication of this manuscript.

\section{Ethics}

Authors should address any ethical issues that may arise after the publication of this manuscript.

\section{References}

Antonescu, P. and F. Petrescu, 1985. An analytical method of synthesis of cam mechanism and flat stick. Proceedings of the 4th International Symposium on Theory and Practice of Mechanisms, (TPM' 85), Bucharest.

Antonescu, P. and F. Petrescu, 1989. Contributions to kinetoplast dynamic analysis of distribution mechanisms. SYROM'89, Bucharest.

Antonescu, P., M. Oprean and F. Petrescu, 1985a. Contributions to the synthesis of oscillating cam mechanism and oscillating flat stick. Proceedings of the 4th International Symposium on Theory and Practice of Mechanisms, (TPM' 85), Bucharest.

Antonescu, P., M. Oprean and F. Petrescu, 1985b. At the projection of the oscillate cams, there are mechanisms and distribution variables. Proceedings of the 5th Conference of Engines, Automobiles, Tractors and Agricultural Machines, Engines and Automobiles, (MEA’ 85), Brasov. 
Antonescu, P., M. Oprean and F. Petrescu, 1986. Designing the profile of the rotating camshaft acting on the oscillating plate with misalignment. Proceedings of the 3rd National Computer-aided Design Symposium in the Field of Mechanics and Machine Organs, (FMR' 86), Brasov.

Antonescu, P., M. Oprean and F. Petrescu, 1987. Dynamic analysis of the cam distribution mechanisms. Proceedings of the 7th National Symposium on Industrial Robots and Space Mechanisms, (RSM' 87), Bucharest.

Antonescu, P., M. Oprean and F. Petrescu, 1988. Analytical synthesis of Kurz profile, rotating the flat cam. Machine Building Magazine Bucharest.

Antonescu, P., F. Petrescu and O. Antonescu, 1994. Contributions to the synthesis of the rotating cam mechanism and the tip of the balancing tip. Brasov.

Antonescu, P., F. Petrescu and D. Antonescu, 1997. Geometrical synthesis of the rotary cam and balance tappet mechanism. SYROM Bucharest, 3: 23-23.

Antonescu, P., F. Petrescu and O. Antonescu, 2000a. Contributions to the synthesis of the rotary disc-cam profile. Proceedings of the 8th International Conference on the Theory of Machines and Mechanisms, (TMM' 00), Liberec, Czech Republic, pp: 51-56.

Antonescu, P., F. Petrescu and O. Antonescu, 2000b. Synthesis of the rotary cam profile with balance follower. Proceedings of the 8th Symposium on Mechanisms and Mechanical Transmissions, (MMT'00), Timişoara, pp: 39-44, 2000.

Antonescu, P., F. Petrescu and O. Antonescu, 2001. Contributions to the synthesis of mechanisms with rotary disc-cam. Proceedings of the 8th IFToMM International Symposium on Theory of Machines and Mechanisms, (TMM' 01), Bucharest, ROMANIA, pp: 31-36.

Aversa, R., R.V.V. Petrescu, A. Apicella and F.I.T. Petrescu, 2017a. Nano-diamond hybrid materials for structural biomedical application. Am. J. Biochem. Biotechnol.

Aversa, R., R.V. Petrescu, B. Akash, R.B. Bucinell and J.M. Corchado et al., 2017b. Kinematics and forces to a new model forging manipulator. Am. J. Applied Sci., 14: 60-80.

Aversa, R., R.V. Petrescu, A. Apicella, F.I.T. Petrescu and J.K. Calautit et al., 2017c. Something about the V engines design. Am. J. Applied Sci., 14: 34-52.

Aversa, R., D. Parcesepe, R.V.V. Petrescu, F. Berto and G. Chen et al., 2017d. Processability of bulk metallic glasses. Am. J. Applied Sci., 14: 294-301.

Aversa, R., R.V.V. Petrescu, B. Akash, R.B. Bucinell and J.M. Corchado et al., 2017e. Something about the balancing of thermal motors. Am. J. Eng. Applied Sci.
Aversa, R., F.I.T. Petrescu, R.V. Petrescu and A. Apicella, 2016a. Biomimetic FEA bone modeling for customized hybrid biological prostheses development. Am. J. Applied Sci., 13: 1060-1067. DOI: 10.3844/ajassp.2016.1060.1067

Aversa, R., D. Parcesepe, R.V. Petrescu, G. Chen and F.I.T. Petrescu et al., 2016b. Glassy amorphous metal injection molded induced morphological defects. Am. J. Applied Sci., 13: 1476-1482.

Aversa, R., R.V. Petrescu, F.I.T. Petrescu and A. Apicella, 2016c. Smart-factory: Optimization and process control of composite centrifuged pipes. Am. J. Applied Sci., 13: 1330-1341.

Aversa, R., F. Tamburrino, R.V. Petrescu, F.I.T. Petrescu and M. Artur et al., $2016 \mathrm{~d}$. Biomechanically inspired shape memory effect machines driven by muscle like acting NiTi alloys. Am. J. Applied Sci., 13: 1264-1271.

Aversa, R., E.M. Buzea, R.V. Petrescu, A. Apicella and M. Neacsa et al., 2016e. Present a mechatronic system having able to determine the concentration of carotenoids. Am. J. of Eng. and Applied Sci., 9: 1106-1111.

Aversa, R., R.V. Petrescu, R. Sorrentino, F.I.T. Petrescu and A. Apicella, 2016f Hybrid ceramo-polymeric nanocomposite for biomimetic scaffolds design and preparation. Am. J. Eng. Applied Sci., 9: 1096-1105.

Aversa, R., V. Perrotta, R.V. Petrescu, C. Misiano and F.I.T. Petrescu et al., 2016g. From structural colors to super-hydrophobicity and achromatic transparent protective coatings: Ion plating plasma assisted $\mathrm{TiO}_{2}$ and $\mathrm{SiO}_{2}$ Nano-film deposition. Am. J. Eng. Applied Sci., 9: 1037-1045.

Aversa, R., R.V. Petrescu, F.I.T. Petrescu and A. Apicella, 2016h. Biomimetic and evolutionary design driven innovation in sustainable products development. Am. J. Eng. Applied Sci., 9: 1027-1036.

Aversa, R., R.V. Petrescu, A. Apicella and F.I.T. Petrescu, 2016i. Mitochondria are naturally micro robots - a review. Am. J. Eng. Applied Sci., 9: 991-1002.

Aversa, R., R.V. Petrescu, A. Apicella and F.I.T. Petrescu, 2016j. We are addicted to vitamins $\mathrm{C}$ and E-A review. Am. J. Eng. Applied Sci., 9: 1003-1018.

Aversa, R., R.V. Petrescu, A. Apicella and F.I.T. Petrescu, 2016k. Physiologic human fluids and swelling behavior of hydrophilic biocompatible hybrid ceramo-polymeric materials. Am. J. Eng. Applied Sci., 9: 962-972.

Aversa, R., R.V. Petrescu, A. Apicella and F.I.T. Petrescu, 20161. One can slow down the aging through antioxidants. Am. J. Eng. Applied Sci., 9: 1112-1126.

Aversa, R., R.V. Petrescu, A. Apicella and F.I.T. Petrescu, 2016m. About homeopathy or $\ll$ Similia Similibus Curentur 》. Am. J. Eng. Applied Sci., 9: 1164-1172. 
Aversa, R., R.V. Petrescu, A. Apicella and F.I.T. Petrescu, 2016n. The basic elements of life's. Am. J. Eng. Applied Sci., 9: 1189-1197.

Aversa, R., F.I.T. Petrescu, R.V. Petrescu and A. Apicella, 2016o. Flexible stem trabecular prostheses. Am. J. Eng. Applied Sci., 9: 1213-1221.

Berto, F., R.V.V. Petrescu and F.I.T. Petrescu, 2016a. A review of recent results on $3 \mathrm{D}$ effects. Am. J. Eng. Applied Sci., 9: 1247-1260.

Berto, F., R.V.V. Petrescu and F.I.T. Petrescu, $2016 \mathrm{~b}$. Three-dimensional in bonded joints: A short review. Am. J. Eng. Applied Sci., 9: 1261-1268.

Berto, F., A. Gagani, R.V.V. Petrescu and F.I.T. Petrescu, 2016c. Key-hole notches in isostatic graphite: A review of some recent data. Am. J. Eng. Applied Sci., 9: 1292-1300.

Berto, F., A. Gagani, R. Aversa, R.V.V. Petrescu and A. Apicella et al., 2016d. Multiaxial fatigue strength to notched specimens made of 40CrMoV13.9. Am. J. Eng. Applied Sci., 9: 1269-1291.

Cao, W., H. Ding, Z. Bin and C. Ziming, 2013. New structural representation and digital-analysis platform for symmetrical parallel mechanisms. Int. J. Adv. Robotic Sys. DOI: 10.5772/56380

Comanescu, A., 2010. Bazele modelarii mecanismelor. E. Politeh. Press, Bucureşti, pp: 274.

Dong, H., N. Giakoumidis, N. Figueroa and N. Mavridis, 2013. Approaching behaviour monitor and vibration indication in developing a General Moving Object Alarm System (GMOAS). Int. J. Adv. Robotic Sys. DOI: $10.5772 / 56586$

Franklin, D.J., 1930. Ingenious mechanisms for designers and inventors. 1st Edn., Industrial Press Inc., New York, pp: ISBN-10: 0831110325, pp: 486.

He, B., Z. Wang, Q. Li, H. Xie and R. Shen, 2013. An analytic method for the kinematics and dynamics of a multiple-backbone continuum robot. IJARS. DOI: $10.5772 / 54051$

Lee, B.J., 2013. Geometrical derivation of differential kinematics to calibrate model parameters of flexible manipulator. Int. J. Adv. Robotic Sys. DOI: $10.5772 / 55592$

Lin, W., B. Li, X. Yang and D. Zhang, 2013. Modelling and control of inverse dynamics for a 5-DOF parallel kinematic polishing machine. Int. J. Adv. Robotic Sys. DOI: 10.5772/54966

Liu, H., W. Zhou, X. Lai and S. Zhu, 2013. An efficient inverse kinematic algorithm for a PUMA560-structured robot manipulator. IJARS. DOI: $10.5772 / 56403$

Mirsayar, M.M., V.A. Joneidi, R.V.V. Petrescu, F.I.T. Petrescu and F. Berto, 2017. Extended MTSN criterion for fracture analysis of soda lime glass. Eng. Fracture Mechanics, 178: 50-59. DOI: 10.1016/j.engfracmech.2017.04.018
Padula, F. and V. Perdereau, 2013. An on-line path planner for industrial manipulators. Int. J. Adv. Robotic Sys. DOI: 10.5772/55063

Perumaal, S. and N. Jawahar, 2013. Automated trajectory planner of industrial robot for pick-andplace task. IJARS. DOI: 10.5772/53940

Petrescu, F. and R. Petrescu, 1995a. Contributions to optimization of the polynomial motion laws of the stick from the internal combustion engine distribution mechanism. ESFA, 1: 249-256.

Petrescu, F. and R. Petrescu, 1995b. Contributions to the synthesis of internal combustion engine distribution mechanisms. ESFA, 1: 257-264.

Petrescu, F. and R. Petrescu, 1997a. Dynamics of cam mechanisms (exemplified on the classic distribution mechanism). SYROM, 3: 353-358.

Petrescu, F. and R. Petrescu, 1997b. Contributions to the synthesis of the distribution mechanisms of internal combustion engines with Cartesian coordinate method. SYROM, 3: 359-364.

Petrescu, F. and R. Petrescu, 1997c. Contributions to maximizing polynomial laws for the active stroke of the distribution mechanism from internal combustion engines. SYROM, 3: 365-370.

Petrescu, F. and R. Petrescu, 2000a. Synthesis of distribution mechanisms by the rectangular (cartesian) coordinate method. University of Craiova.

Petrescu, F. and R. Petrescu, 2000b. The design (synthesis) of cams using the polar coordinate method (the triangle method). Proceedings of the Grafica Conference, University of Craiova, (CUC' 00 ), Craiova.

Petrescu, F. and R. Petrescu, 2002a. Motion laws for camshafts. Proceedings of the 7th National Symposium with International Participation Computer Assisted Design, (CAD’ 02), Braşov, pp: 321-326.

Petrescu, F. and R. Petrescu, 2002b. Camshaft dynamics elements. Proceedings of the 7th National Symposium on International Computer Assisted Design (PAC' 02), Braşov, pp: 327-332.

Petrescu, F. and R. Petrescu, 2003. Some elements regarding the improvement of the engine design. Proceedings of the 8th National Symposium, Descriptive Geometry, Technical Graphics and Design, (GTD ‘03), Brasov, pp: 353-358.

Petrescu, F. and R. Petrescu, 2005a. The cam design for a better efficiency. Proceedings of the International Conference on Engineering Graphics and Design, (EGD' 05), Bucharest, pp: 245-248.

Petrescu, F. and R. Petrescu, 2005b. Contributions at the dynamics of cams. Proceedings of the 9th IFToMM International Symposium on Theory of Machines and Mechanisms, (TMM' 05), Bucharest, Romania, pp: 123-128.

Petrescu, F. and R. Petrescu, 2005c. Determining the dynamic efficiency of cams. Proceedings of the 9th IFToMM International Symposium on Theory of Machines and Mechanisms, (TMM' 05), Bucharest, Romania, pp: 129-134. 
Petrescu, F. and R. Petrescu, 2005d. An original internal combustion engine. Proceedings of the 9th IFToMM International Symposium on Theory of Machines and Mechanisms, (TMM' 05), Bucharest, Romania, pp: $135-140$.

Petrescu, F. and R. Petrescu, 2005e. Determining the mechanical efficiency of Otto engine's mechanism. Proceedings of the 9th IFToMM International Symposium on Theory of Machines and Mechanisms, (TMM' 05), Bucharest, Romania, pp: 141-146.

Petrescu, F.I. and R.V. Petrescu, 2011. Mechanical Systems, Serial and Parallel - Course (in romanian). 1st Edn., LULU Publisher, London, UK, pp: 124.

Petrescu, F.I. and R.V. Petrescu, 2012a. Kinematics of the planar quadrilateral mechanism. Engevista, 14: 345-348.

Petrescu, F.I. and R.V. Petrescu, 2012b. MecatronicaSisteme Seriale Si Paralele. 1st Edn., Create Space Publisher, USA, pp: 128.

Petrescu, F.I. and R.V. Petrescu, 2013a. Cinematics of the 3R Dyad. Engevista, 15: 118-124.

Petrescu, F.I., Petrescu, R.V., 2013b. Forces and efficiency of cams. Int. Rev. Mechanical Eng.

Petrescu, F.I. and R.V. Petrescu, 2016a. Parallel moving mechanical systems kinematics. ENGEVISTA, 18: 455-491.

Petrescu, F.I. and R.V. Petrescu, 2016b. Direct and inverse kinematics to the anthropomorphic robots. ENGEVISTA, 18: 109-124.

Petrescu, F.I. and R.V. Petrescu, 2016c. Dynamic cinematic to a structure 2R. Revista Geintec-Gestao Inovacao E Tecnologias, 6: 3143-3154.

Petrescu, R.V., R. Aversa, B. Akash, R. Bucinell and J. Corchado et al., 2017a. Yield at thermal engines internal combustion. Am. J. Eng. Applied Sci., 10: 243-251.

Petrescu, R.V., R. Aversa, B. Akash, B. Ronald and J. Corchado et al., 2017b. Velocities and accelerations at the 3R mechatronic systems. Am. J. Eng. Applied Sci., 10: 252-263.

Petrescu, R.V., R. Aversa, B. Akash, R. Bucinell and J. Corchado et al., 2017c. Anthropomorphic solid structures n-R kinematics. Am. J. Eng. Applied Sci., 10: 279-291.

Petrescu, R.V., R. Aversa, B. Akash, R. Bucinell and J. Corchado et al., 2017d. Inverse kinematics at the anthropomorphic robots, by a trigonometric method. Am. J. Eng. Applied Sci., 10: 394-411.
Petrescu, R.V., R. Aversa, B. Akash, R. Bucinell and J. Corchado et al., 2017e. Forces at internal combustion engines. Am. J. Eng. Applied Sci., 10: 382-393.

Petrescu, RV., R. Aversa, B. Akash, R. Bucinell and J. Corchado et al., 2017f. Gears-part I. Am. J Eng. Applied Sci., 10: 457-472.

Petrescu, R.V., R. Aversa, B. Akash, R. Bucinell and J. Corchado et al., 2017g. Gears-Part II. Am. J. Eng. Applied Sci., 10: 473-483.

Petrescu, R.V., R. Aversa, B. Akash, R. Bucinell and J. Corchado et al., 2017h. Cam-gears forces, velocities, powers and efficiency. Am. J. Eng. Applied Sci., 10: 491-505.

Petrescu, R.V., R. Aversa, B. Akash, R. Bucinell and J. Corchado et al., 2017i. Dynamics of mechanisms with cams illustrated in the classical distribution. Am. J. Eng. Applied Sci., 10: 551-567.

Petrescu, R.V., R. Aversa, B. Akash, R. Bucinell and J. Corchado et al., 2017j. Testing by non-destructive control. Am. J. Eng. Applied Sci., 10: 568-583.

Petrescu, R.V., R. Aversa, A. Apicella and F.I.T. Petrescu, 2017k. Transportation engineering. Am. J. Eng. Applied Sci., 10: 685-702.

Petrescu, R.V., R. Aversa, S. Kozaitis, A. Apicella and F.I.T. Petrescu, 20171. The quality of transport and environmental protection, part I. Am. J. Eng. Applied Sci., 10: 738-755.

Petrescu, R.V., R. Aversa, A. Apicella and F.I. Petrescu, 2016. Future medicine services robotics. Am. J. Eng. Applied Sci., 9: 1062-1087.

Petrescu, F.I., B. Grecu, A. Comanescu and R.V. Petrescu, 2009. Some mechanical design elements. Proceeding of the International Conference on Computational Mechanics and Virtual Engineering, (COMEC' 2009), Braşov, pp: 520-525.

Petrescu, F.I., 2011. Teoria Mecanismelor si a Masinilor. 1st Edn., Create Space Publisher, USA, pp: 432.

Petrescu, F.I.T., 2015a. Geometrical synthesis of the distribution mechanisms. Am. J. Eng. Applied Sci., 8: 63-81.

Petrescu, F.I.T., 2015b. Machine motion equations at the internal combustion heat engines. Am. J. Eng. Applied Sci., 8: 127-137. 